\title{
Dignidad de la tecnología y tecnología de la dignidad
}

Wilson Hernando Soto Urrea*

Resumen. En este artículo se presenta la concepción de dignidad humana en relación con lo económico y lo social en el imaginario social, con el fin de comprender, a partir del pensamiento kantiano, una supuesta dignificación de la tecnología.

Palabras clave. Imaginarios sociales, dignidad, tecnología.

Abstract. In this paper we present the concept of human dignity in relation with the social and economic aspects ofsocial imaginary, in order to understand a supposed dignity of technology, from Kantian thought.

Keywords. Social imaginary, dignity, technology.

\section{Introducción. Imaginarios sociales}

El escritor irlandés George Bernard Shaw decía que: «Tanto los optimistas como los pesimistas contribuyeron al progreso de la humanidad. Los optimistas inventaron el avión, los pesimistas

* Ing. Mecánico, Universidad Nacional de Colombia. Magíster en Educación Universidad Pedagógica Nacional. Candidato a Doctor, Universidad Pedagógica Nacional, Universidad Distrital, Universidad del Valle. Profesor Asociado Universidad de San Buenaventura, sede Bogotá. 
inventaron el paracaídas» (Correa, 2001, p. 121). Permítaseme en este breve artículo ser parte del equipo de inventores del paracaídas.

Por estos días, debido a la desgracia vivida en el Japón, se volvió un tema de obligada discusión la energía nuclear, por aquello del reactor de Fukushima, que revivió el imaginario social de que la energía atómica es la principal fuente de energía del siglo XXI y que pronto la eólica y la solar serán el futuro energético. iFalso!: la principal fuente de energía mundial es aquella que estamos acostumbrados a ver en los trenes de las películas del salvaje oeste gringo, es decir, el carbón. De ahí que Estados Unidos, China y Rusia tengan y compren grandes reservas de carbón.

Otro imaginario social, y que ha gozado de gran discursividad y despliegue publicitario, nace de la discusión de los padres de la física cuántica. Einstein no creía posible que la física a nivel del cuanto fuera probabilística. Años más tarde se demostraría cuán equivocado estaba y por eso afirmó que «Dios no juega a los dados» (Einstein, citado por Kaku, 2005, p.131). A mi parecer, la afirmación trascendente es la dada por Niels Bohr (el mismo que conocimos en el bachillerato cuando nos explicaron la estructura clásica del átomo) «Pero es que no es asunto nuestro prescribir a Dios como tiene que regir el mundo» (Matthai, 2002, 143). Como señala Pascual Pont (2004), resulta curioso que se hayan repetido hasta la saciedad las palabras de Einstein y en cambio apenas si se conoce la réplica de Bohr.

\section{Dignidad $\epsilon$ imaginario social}

Traje estos dos imaginarios a colación por dos razones. Primera, la dignidad en el imaginario social se ha convertido en sinónimo de estatus social y de éxito económico, para la muestra, no un botón, sino un diccionario. El Diccionario Práctico del Estudiante 
avalado por la Real Academia de la Lengua y la Asociación de Academias de la lengua española define la dignidad como:

1. Cualidad de digno, específicamente en la manera de comportarse. Ejemplo en cursiva. El sueldo le permite vivir con dignidad. 2. Cargo o título honoríficos y de autoridad. Ejemplo en cursiva. Los monarcas ostentan muchas dignidades.

Creo que al igual que lo sucedido con Bohr, como sociedad hemos olvidado lo que los grandes pensadores y filósofos nos han dicho sobre la dignidad. En aras de la brevedad sólo me detendré en esbozar la concepción de dignidad de Kant, descrita en la Fundamentación de la metafísica de las costumbres:

Cuanto se refiere a las inclinaciones y necesidades humanas tiene un precio de mercado; lo que, sin suponer una necesidad, se adecuó a cierto gusto, es decir, a un bienestar basado en el juego sin propósito de nuestras facultades anímicas [un objeto estético, por ejemplo, o un objeto particularmente vinculado a nuestros sentimientos], tiene un precio de afecto; pero lo que constituye la condición única bajo la cual algo puede ser fin en sí mismo no tiene meramente un valor relativo, o sea un precio, sino que tiene un valor intrínseco, es decir, dignidad. (Kant, 1999, p. 145).

Esta conceptualización declara la diferencia radical entre precio y dignidad explicando que la noción de precio de mercado se aplica propiamente al intercambio de bienes económicos, y menos propiamente (precio de afecto) a los objetos estéticos o a aquellos a los que nos vinculamos sentimentalmente (un objeto que nos recuerda, por ejemplo, a una persona amada o una vivencia intensa). De ninguna manera, sin embargo, puede aplicarse a una persona física porque, valiendo ésta por sí misma, no tiene valor equivalente, no tiene valor de cambio, no tiene precio. Tiene dignidad, dice Kant. 


\section{Dignidad y tecnología}

Mi hipótesis es que se ha creado un imaginario social de dignificación de la tecnología porque se cree que es el único camino para una vida mejor, a pesar de lo dicho por Kant. Por ejemplo, en su discurso de posesión como presidente de los Estados Unidos en 1949, Harry Truman declaraba que:

Más de la mitad de la población del mundo vive en condiciones cercanas a la miseria. Su alimentación es inadecuada, es víctima de la enfermedad. Su vida económica es primitiva y está estancada. Su pobreza constituye un obstáculo y una amenaza tanto para ellos como para las áreas más prosperas. Por primera vez en la historia, la humanidad posee el conocimiento y la capacidad para aliviar el conocimiento de estas gentes... Creo que deberíamos poner a disposición de los amantes de la paz los beneficios de nuestro acervo de conocimiento técnico para ayudarlos a lograr sus aspiraciones de una vida mejor... Lo que tenemos en mente es un programa de desarrollo basado en los conceptos del trato justo y democrático... Producir más es la clave para la paz y la prosperidad. Y la clave para producir más es una aplicación mayor y más vigorosa del conocimiento técnico y científico moderno. (Truman, citado por Escobar, 1999, p. 33).

Esta política, a decir de las Naciones Unidas en 1951, sólo era posible:

Con ajustes dolorosos. Las filosofías ancestrales deben ser erradicadas, las viejas instituciones sociales tiene que desintegrarse; los lazos de casta, credo y raza deben romperse; y grandes masas de personas incapaces de seguir el ritmo del progreso deberán ver frustradas sus expectativas de una vida cómoda. Muy pocas comunidades están dispuestas a pagar el precio del progreso económico. (Naciones Unidas, citado por Escobar, 1999, p. 34). 
En la actual sociedad, caracterizada entre otros factores por la inversión de algunos valores -no en vano cuando se va en automóvil y se quiere ir hacia la derecha debemos girar hacia la izquierda- se ha tratado de vender el imaginario de que la dignidad es exterioridad, un afuera, sólo alcanzable por el camino del éxito económico y del reconocimiento social. En una sociedad de control, a decir de Deleuze (1999), que trata de clasificar al ser humano y a la máquina por igual según el grado de información y de comunicación que pueda ofrecer, es tarea urgente como educadores, erradicar las discursividades que buscan dignificar los avances tecnológicos y trabajar por una búsqueda de la dignidad inherente sólo al ser humano.

Estimados compañeros de oficio, del oficio de enseñar, quiero por último invitarlos sin limitaciones de tiempo acelerado que nos impone esta sociedad, a que reflexionemos y busquemos nuestra dignidad como maestros, no en sueldos elevados, ni en reconocimientos académicos, ni en el manejo de herramientas virtuales, sino en lo esencial, en lo verdaderamente importante en nuestro interior. Porque maestros que buscan su dignidad en el afuera sólo serán capaces de instruir a sus alumnos, de la misma forma que instruiría un computador con herramientas virtuales: maestros que en su interior buscan su dignidad son los llamados a formar las generaciones de la era cibernética.

\section{Bibliografía}

Deleuze, G. (1999). Conversaciones. Valencia: Pre-Textos.

Escobar, A. (1999). El final del salvaje: naturaleza, cultura y política en la antropología contemporánea. Bogotá: Centro de Estudios de la Realidad Colombiana.

Kant, I. (1999). Fundamentación de la metafísica de las costumbres. (J. Mardomingo, Trad.) Barcelona: Ariel. 
Kaku, M. (2005). El universo de Einstein: cómo la visión de Albert Einstein transformó nuestra comprensión del espacio y el tiempo. Barcelona: Antoni Bosch.

Matthai, H. (2002). Textos filosóficos 1989-1999. California: Universidad de Baja California.

Pont, Pascual. (2004). La gravedad monádica. Valencia: Universidad Politécnica de Valencia.

Real Academia Española. (2006). Diccionario. Madrid: Santillana.

Recibido en abril de ZOII Arbitrado $\in$ junio de 2OII 